\title{
Effects of prescribed antihypertensives and other cardiovascular drugs on mortality in patients with atrial fibrillation and hypertension: a cohort study from Sweden
}

\begin{abstract}
Axel C Carlsson ${ }^{1,2}$, Per Wändell ${ }^{1}$, Kristina Sundquist ${ }^{3,4}$, Sven-Erik Johansson ${ }^{3}$ and Jan Sundquist ${ }^{3,4}$
Although antihypertensive drugs are known to reduce mortality in individuals with hypertension, the effects of different cardiovascular pharmacotherapies on mortality among patients with hypertension and atrial fibrillation (AF) have been less thoroughly explored. To study mortality rates in men and women separately with hypertension and AF prescribed different cardiovascular pharmacotherapies. A cohort of men $(n=2809)$ and women $(n=2793)$ aged $>45$ years diagnosed with hypertension and AF were selected using patient records. Hazard ratios (HRs) with 95\% confidence intervals (Cls) were calculated using Cox regression, with all-cause mortality as the outcome. Analysis was performed on the whole population and after stratification by age and sex. Independent factors were prescribed pharmacotherapies. Adjustments were made for a propensity score comprising age, comorbidities, education and marital status. The higher the number of antihypertensive drugs prescribed, the lower the mortality rate $(P$-value for trend 0.005$)$. Individuals prescribed $4-5$ antihypertensive drugs had a lower risk of mortality than those prescribed 0-1 drugs (HR: $0.62 ; 95 \% \mathrm{Cl}: 0.45-0.86$ ). The HRs for the following drug classes were: loop diuretics 1.39 (95\% Cl: 1.08-1.78), non-selective $\beta$-blockers 0.68 (95\% Cl: $0.53-0.88)$, angiotensin receptor blockers $0.75(95 \% \mathrm{Cl}: 0.56-0.99)$ and statins 0.68 (95\% $\mathrm{Cl}: 0.53-0.88)$. AF patients with hypertension prescribed statins, non-selective $\beta$-blockers and angiotensin receptor blockers had low relative mortality risks, suggesting that these prescribed pharmacotherapies were beneficial. This needs to be further explored in other clinical settings.
\end{abstract}

Hypertension Research (2014) 37, 553-559; doi:10.1038/hr.2014.32; published online 6 March 2014

Keywords: calcium antagonists; diuretics; pharmacotherapy; propensity score statins

\section{INTRODUCTION}

Hypertension is treated with five main classes of antihypertensive pharmacotherapies that have been tested extensively in clinical trials: diuretics, $\beta$-blockers, angiotensin-converting enzyme (ACE) inhibitors, angiotensin receptor blockers (ARBs) and calcium antagonists. ${ }^{1}$ The most important aim of antihypertensive drug treatment is to reduce effectively vascular complications. Randomized controlled trials have previously shown that large reductions in the risk of macrovascular complications were achieved by large reductions in blood pressure and that treatment with any commonly used antihypertensive pharmacotherapy reduced the risk of major cardiovascular events. ${ }^{2-5}$ However, little is known about the effects of antihypertensive pharmacotherapies on mortality risk among patients with hypertension and concomitant atrial fibrillation (AF), as patients with comorbidities are often excluded from randomized trials. ${ }^{6}$
AF is the most common arrhythmia and its age- and sex-adjusted prevalence has been estimated at $1.4 \%$ in the Swedish population, with the prevalence of chronic AF being 1.0\%, ${ }^{7}$ values consistent with those from studies from other countries $(1-1.5 \%$ of the population). ${ }^{8,9}$ The lifetime risk of developing $\mathrm{AF}$ is, however, much higher, with AF estimated to affect about one-quarter of the population in Western countries. ${ }^{8}$ Hypertension is common among patients with AF. In a recent study, we showed that, in Sweden, 30\% of men and $34 \%$ of women with AF attending primary health-care centers (PHCCs) were diagnosed with concomitant hypertension. ${ }^{10}$

As well as lowering blood pressure, antihypertensive pharmacotherapies exert additional effects on AF symptoms. First, selectiveand non-selective $\beta$-blockers, which control the heart rhythm, are commonly prescribed to AF patients. Prescription of selective $\beta$-blockers has increased among patients with AF in primary care,

${ }^{1}$ Centre for Family Medicine, Karolinska Institutet, Huddinge, Stockholm, Sweden; ${ }^{2}$ Department of Medical Sciences, Molecular Epidemiology and Science for Life Laboratory, Uppsala University, Uppsala Sweden; ${ }^{3}$ Center for Primary Health Care Research, Lund University/Region Skåne, Malmö, Sweden and ${ }^{4}$ Stanford Prevention Research Center, Stanford University School of Medicine, Palo Alto, CA, USA

Correspondence: Dr AC Carlsson, Centre for Family Medicine, Karolinska Institutet, Alfred Nobels Allé 12, Huddinge, Stockholm 141 83, Sweden.

E-mail: axelcefam@hotmail.com

Received 12 June 2013; revised 17 October 2013; accepted 12 November 2013; published online 6 March 2014 
whereas prescription of non-selective $\beta$-blockers, such as sotalol, has decreased. ${ }^{11}$ Heart-active calcium antagonists are also of particular interest as they are prescribed to patients with $\mathrm{AF}$ to control the heart rate. Diuretics, which affect ion concentrations in the blood and consequently heart function, may be useful in treating arrhythmias such as AF. Apart from the five main classes of antihypertensive pharmacotherapies, potassium-saving diuretics (eplerenone, spironolactone and amiloride) ${ }^{12}$ are often prescribed to patients who are resistant to treatment with common antihypertensive drugs. ${ }^{13}$ Potassium-saving diuretics recapture potassium from urine and are recommended for use in patients with low potassium levels, such as patients on loop diuretics.

We hypothesize that prescription of antihypertensive drug classes may be associated with different all-cause mortality risks in patients with $\mathrm{AF}$ and concomitant hypertension. Moreover, there may be risk differences with regard to gender. Accordingly, the main aim of this study was to investigate the association between mortality risk and prescribed antihypertensives and other cardiovascular drugs in a cohort of 5602 hypertensive men and women with AF attending primary care centers in Sweden, with a mean follow-up time of 3.4 years. Age, cardiovascular comorbidities, education and marital status, which were established covariate factors that may influence mortality outcomes in men and women with $\mathrm{AF}$ and hypertension were accounted for.

\section{METHODS}

\section{Design}

The study used individual-level patient data from 75 PHCCs, most of which are located in Stockholm County $(n=48)$. Individuals attending any of the participating PHCCs between 2001 and 2008 were included in the study. We used Extractor software (http://www.slso.sll.se/SLPOtemplates/SLPOPagel__10400.aspx; accessed 19 September 2010) to extract individual electronic patient records. National identification numbers were replaced with a new unique serial number to ensure anonymity.

The patient files were linked to data from the Total Population register, the In-patient Register and the Cause of Death Register, ${ }^{14}$ including individuallevel data on age, gender, education and hospital admissions for all residents registered in Sweden. In this way, a new research database containing clinical and socioeconomic data on the 1098420 individuals registered at the 75 PHCCs was created.

\section{Study population}

All persons diagnosed with both hypertension and AF who attended the 75 PHCCs between 1 January 2001 and 31 December 2007 were included in this study. They were identified by the ICD-10 codes (10th version of the World Health Organization's International Classification of Diseases) for AF (I48) and hypertension (I10-15) in the patients' medical records. In total, 2809 men and 2793 women $\geqslant 45$ years of age at the time of their AF and hypertension diagnoses were identified and included. ${ }^{15}$

\section{Comorbidities}

The following cardiovascular disorders were used as covariates: coronary heart disease (I20-25), congestive heart failure (CHF; I50 and I110) and cerebrovascular diseases (I60-69), including intracranial bleeding (I60-62) and peripheral embolism (I74). In addition, the presence of diabetes mellitus (E10-14) was recorded.

\section{Outcome variable}

Time to death in the period between registration of the AF diagnosis and 31 December 2007.

Demographic, marital status and socioeconomic variables Gender: Men and women.
Individuals were divided into the following age groups: 45-54, 55-64, 65-74, $75-84$ and $\geqslant 85$ years. Individuals younger than 45 years were excluded. Age was also included in the analysis as a continuous variable (see Statistical analysis).

Educational level was categorized as $\leqslant 9$ years (partial or complete compulsory schooling), 10-12 years (partial or complete secondary schooling) and $>12$ years (college and/or university studies).

\section{Pharmacotherapies}

Drugs prescribed in primary health care during the assessment period were recorded using the Anatomic Therapeutic Chemical Classification. Diuretic drugs (C03) were classified as thiazides, related agents, combined formulations with other drugs (C03A, C03B, C03E, C09B C09DA), loop diuretics (C03C) or potassium-saving diuretics (C03D), including aldosterone antagonists (C03DA). $\beta$-Blockers (C07) were divided into $\beta 1$-selective and non-selective agents, that is, mostly sotalol (C07AA07) ${ }^{16}$ Calcium receptor-blocking agents (C08) were divided into vessel-selective (C08C, C09DB) and heart-selective agents (C08DB). Renin-angiotensin system (RAS) blockers were divided into ACE inhibitors (C09A) and ARBs (C09C). Lipid-lowering drugs (C10A), where statins (C10AA) dominated, were also included as a covariate.

In terms of prescription of antithrombotic drugs (B01A), patients were divided into three groups: no treatment, antiplatelet treatment (B01AC) and anticoagulant treatment (B01AA) (with or without antiplatelet treatment).

\section{Statistical analysis}

Differences in means and distributions between men and women were calculated using Student's $t$-test, $\chi^{2}$ analysis and Fisher's exact test.

Follow-up analyses were performed using Cox regression (hazard ratios (HRs)), with time to death as the outcome. Analyses were performed separately for men and women, and for individuals aged $<80$ and $\geqslant 80$ years, to minimize the effects of interactions between age and sex. Eighty years has been commonly referred to as a cutoff age for stroke prophylaxis, ${ }^{17}$ as well as an age of increased prevalence and incidence of $\mathrm{AF}^{18}$ Furthermore, the number of deceased women aged $<75$ years was too low $(n=63)$ to provide reliable results. Statistical power calculations for Cox regression with a dichotomous variable were performed with $80 \%$ power and an $\alpha$-value of 0.05 to ensure sufficient detection of HRs in men and women.

A propensity score was estimated for each drug class separately. ${ }^{19}$ In Model A, the propensity scores included age group, cardiovascular comorbidity (diabetes, coronary heart disease, CHF and cerebrovascular diseases), educational level and marital status. In Model B, the propensity scores included all variables in Model A and all the antihypertensive drugs, antithrombotics and statins.

We also analyzed the association between the number of antihypertensive drugs prescribed and mortality in multivariable Cox regression models, adjusted for the propensity score in Model A with the addition of antithrombotic drugs, digitalis, loop diuretics and statins. Men and women were analyzed separately. The same association was analyzed in multivariable Cox regression models of the population as a whole adjusted for all the variables listed above, including sex.

A $P$-value for two-sided tests of $<0.01$ was considered to be statistically significant owing to the multiple comparisons between men and women. A $P$-value of $<0.05$ was considered statistically significant in the Cox regression analyses.

Stata 11.2 software (College Station, TX, USA) was used to perform all calculations.

\section{RESULTS}

The mean follow-up time was 3.4 years (s.d. 2.1). The regression models were based on a total of 19283 person-years at risk. Table 1 shows the characteristics of the 2809 men and 2793 women included in the study. A total of 212 men and 278 women died during followup $(7.6 \%$ vs. $10.0 \% ; P<0.001)$. Using these figures in our power calculations, we found that we had enough power to detect HRs $>1.5$ or $<0.67$ in both men and women. 
Table 1 Characteristics of patients aged $\geqslant 45$ years with diagnosed atrial fibrillation and hypertension $(n=5602)$ attending 75 primary health-care centers in Sweden between 1 January 2001 and 31 December 2007

\begin{tabular}{|c|c|c|c|c|c|c|}
\hline & \multicolumn{2}{|c|}{ Men } & \multicolumn{2}{|c|}{ Women } & \multicolumn{2}{|c|}{ Sex difference } \\
\hline & All & Dead & $A / l$ & Dead & $A / l$ & Dead \\
\hline & n (\%) & $\mathrm{n}(\%)$ & n $(\%)$ & n (\%) & $\mathrm{P}$-value & P-value \\
\hline Number of patients & 2809 & $212(7.6)$ & 2793 & $278(10.0)$ & & 0.001 \\
\hline Age (years), mean (s.d.) & $72.3(9.2)$ & & $77.2(8.6)$ & & $<0.001$ & \\
\hline \multicolumn{7}{|l|}{ Age (years) $<0.001$} \\
\hline $45-54$ & $103(3.7)$ & $2(1.9)$ & $33(1.2)$ & $0(0.0)$ & & 0.57 \\
\hline $55-64$ & 495 (17.6) & $12(2.4)$ & $223(8.0)$ & $4(1.8)$ & & 0.60 \\
\hline $65-74$ & $963(34.3)$ & $42(4.4)$ & $642(23.0)$ & $22(3.4)$ & & 0.35 \\
\hline $75-79$ & $571(20.3)$ & $54(9.5)$ & $641(23.0)$ & $50(7.8)$ & & 0.30 \\
\hline $80-84$ & 459 (16.3) & $57(12.4)$ & $708(25.4)$ & $85(12.0)$ & & 0.83 \\
\hline $85+$ & $218(7.8)$ & $45(20.6)$ & $546(20.0)$ & $117(21.4)$ & & 0.81 \\
\hline Educational level & & & & & $<0.001$ & \\
\hline Compulsory school & $1123(41.7)$ & $90(8.0)$ & $1403(55.8)$ & $140(10.0)$ & & 0.088 \\
\hline Secondary school & $1020(37.8)$ & $67(6.6)$ & 787 (31.3) & $49(6.2)$ & & 0.77 \\
\hline College/university & $553(20.5)$ & $30(5.4)$ & $323(12.9)$ & $11(3.4)$ & & 0.17 \\
\hline Marital status & & & & & $<0.001$ & \\
\hline Married & $1712(61.1)$ & $122(7.1)$ & $850(30.5)$ & $69(8.1)$ & & 0.37 \\
\hline Unmarried & $247(8.8)$ & $11(4.5)$ & $190(6.8)$ & $14(7.4)$ & & 0.19 \\
\hline Divorced & $420(15.0)$ & $30(7.1)$ & 377 (13.5) & $32(8.5)$ & & 0.48 \\
\hline Widowed & $423(15.1)$ & $46(10.9)$ & $1369(49.1)$ & $161(11.8)$ & & 0.62 \\
\hline \multicolumn{7}{|l|}{ Diagnosis } \\
\hline Coronary heart disease & $596(21.2)$ & $55(9.2)$ & $623(22.3)$ & $83(13.3)$ & 0.32 & 0.024 \\
\hline Heart failure & $403(14.4)$ & $49(12.2)$ & $491(17.6)$ & $81(16.5)$ & 0.001 & 0.067 \\
\hline Cerebrovascular disease & $371(13.2)$ & $23(6.2)$ & $351(12.6)$ & $46(13.1)$ & 0.47 & 0.002 \\
\hline Diabetes mellitus & $789(28.1)$ & $53(6.7)$ & $677(24.2)$ & $70(10.3)$ & 0.001 & 0.013 \\
\hline
\end{tabular}

Those who died during the follow-up period are shown separately, as well as being included in the whole study sample.

Men were significantly younger and more highly educated than were women. More women were widows than men were widowers. Heart failure was more common among women than among men (17.6\% vs. $14.4 \%, P<0.001$ ), whereas diabetes was more common among men than among women $(28.1 \%$ vs. $24.2 \%)$ (Table 1$)$.

Table 2 shows prescription rates of pharmacotherapies (with Anatomic Therapeutic Chemical codes) in men and women. Women were more frequently prescribed antiplatelets, digitalis, loop diuretics, thiazides, potassium-saving agents and aldosterone antagonists than were men, whereas men were more frequently prescribed anticoagulant agents, RAS-blocking agents, ACE inhibitors, lipid-lowering drugs and statins than were women.

Tables $3 \mathrm{a}$ and $\mathrm{b}$ show Cox regression models for men and women, respectively, stratified by age ( $<80$ and $\geqslant 80$ years). After adjustments for a comprehensive propensity score including all pharmacotherapies, we found that prescription of anticoagulants and statins were associated with lower mortality in men aged $<80$ years, whereas prescription of ARBs were associated with lower mortality in men aged $\geqslant 80$ years. When men of all ages were analyzed, anticoagulants were associated with lower mortality in comparison with no treatment, as well as in comparison with antiplatelets. Thiazides and statins were also associated with lower mortality in models of men in all ages. Prescription of thiazides and loop diuretics was associated with higher mortality and statins were associated with lower mortality in women aged $<80$ years after adjustment for a propensity score including all pharmacotherapies. No significant associations between prescribed pharmacotherapies and mortality were observed in women aged $\geqslant 80$ years. ARBs and statins were associated with lower mortality and loop diuretics with higher mortality when women of all ages were analyzed.

In the full model, in which men and women were analyzed together, individuals aged $<80$ years prescribed anticoagulants $v s$. antiplatelets had HR 0.65 (95\% CI: 0.47-0.90), loop diuretics an HR of 1.53 (95\% CI: $1.07-2.20)$, ARBs of 0.56 (95\% CI: $0.34-0.93)$ and statins of 0.44 (95\% CI: $0.30-0.65)$. In individuals aged $\geqslant 80$ years, ARBs had HR of 0.60 (95\% CI: $0.37-0.99)$ and ARBs vs. ACE inhibitors 0.58 (95\% CI: 0.36-0.93) (data not shown in tables).

In the full regression model of the whole study sample adjusted for sex and all other covariates, individuals prescribed anticoagulants vs. no treatment had HR 0.67 (95\% CI: 0.45-0.99), anticoagulants vs. antiplatelets 0.78 (95\% CI: $0.62-0.97)$ and non-selective $\beta$-blockers vs. $\beta 1$-selective $\beta$-blockers 0.62 (95\% CI: 0.41-0.95). Furthermore, individuals prescribed loop diuretics had an HR of 1.42 (95\% CI: 1.10-1.82), ARBs of 0.59 (95\% CI: 0.41-0.83), ARBs vs. ACE inhibitors 0.70 (95\% CI: $0.50-0.97$ ), ARBs combined with thiazides 0.62 (95\% CI: $0.39-0.98)$ and statins of 0.64 (95\% CI: $0.49-0.83$ ) (data not shown in tables).

The fully adjusted models of the effect of the number of different antihypertensive drugs prescribed are shown in Table 4 . In the sexadjusted model of the whole study sample, using $0-1$ prescribed hypertensive drugs as the reference, a general trend was observed $(P=0.005)$ whereby the higher the number of antihypertensive drugs 
Table 2 Cardiovascular pharmacotherapies prescribed to patients aged $\geqslant 45$ years with diagnosed atrial fibrillation and hypertension $(n=5602)$ attending 75 primary health-care centers in Sweden between 1 January 2001 and 31 December 2007

\begin{tabular}{|c|c|c|c|}
\hline All antithrombotic agents (BO1A) & $2560(91.1)$ & $2502(89.6)$ & 0.049 \\
\hline Anticoagulant agents (B01AA) & $1667(59.3)$ & $1400(50.1)$ & $<0.001$ \\
\hline Aspirin (B01AC6, B01AC30) & $1678(59.7)$ & $1805(64.6)$ & $<0.001$ \\
\hline Digitalis $(\mathrm{CO1A})$ & $778(27.7)$ & 1104 (39.5) & $<0.001$ \\
\hline Any diuretic treatment ( $\mathrm{CO}$ ) & $2021(72.0)$ & $2324(83.2)$ & $<0.001$ \\
\hline Loop diuretics (C03C) & $1335(47.5)$ & $1600(57.3)$ & $<0.001$ \\
\hline Thiazides (C03A, C03B, C03E, C09B C09DA) & $1177(39.8)$ & $1296(46.4)$ & $<0.001$ \\
\hline Any potassium-saving agent (CO3D) & $797(28.4)$ & 1085 (38.9) & $<0.001$ \\
\hline Aldosterone antagonists (CO3DA) & $382(13.6)$ & 469 (16.8) & 0.001 \\
\hline Ca-blocking agents (CO8) & $1363(48.5)$ & $1358(48.6)$ & 0.94 \\
\hline Vessel selective Ca blockers (C08C, C09DB) & $1210(43.1)$ & $1137(40.7)$ & 0.073 \\
\hline Heart-active Ca blockers (C08D) & $210(7.5)$ & 305 (10.9) & $<0.001$ \\
\hline RAS-blocking agents (CO9) & 1992 (70.9) & $1728(61.9)$ & $<0.001$ \\
\hline ACE inhibitors (C09A, C09B) & $1516(54.0)$ & $1241(44.4)$ & $<0.001$ \\
\hline ARBs (C09C, C09D) & $827(29.4)$ & $814(29.1)$ & 0.81 \\
\hline All lipid-lowering drugs (C1OA) & $1094(40.0)$ & $913(32.7)$ & $<0.001$ \\
\hline Statins (C10AA) & $1068(38.0)$ & $894(32.0)$ & $<0.001$ \\
\hline
\end{tabular}

Abbreviations: ACE, angiotensin-converting enzyme; ARB, angiotensin receptor blockers; RAS, renin-angiotensin system. RAS-blocking agents include both ACE inhibitors and ARBs.

prescribed the lower the mortality rate. Interestingly, individuals prescribed 4-5 antihypertensive drugs had an HR of 0.62 (95\% CI: 0.45-0.86) (Table 4).

\section{DISCUSSION}

In this study of a large number of patients with both AF and hypertension in which over 19000 patient-years of risk were analyzed, none of the main antihypertensive drug classes prescribed was associated with either an increased or decreased risk in all subgroups. Nevertheless, a general trend was observed whereby the higher the number of antihypertensive drugs prescribed the lower the mortality rate. Prescription of statins was associated with lower mortality in men and women aged $<80$ years, whereas prescription of loop diuretics and thiazides was associated with higher mortality in women aged $<80$ years. Across the whole study population, prescription of loop diuretics was associated with high mortality, whereas prescription of anticoagulants, non-selective $\beta$-blockers, ARBs and statins was associated with lower mortality.

Prescription of a high number of antihypertensive drugs to AF patients with hypertension tended to result in lower mortality, suggesting that the more antihypertensive drugs administered, the better the protective effect they exert in controlling hypertension. This overall protective effect of multiple antihypertensive drugs could be explained by the poor blood pressure control in Sweden, ${ }^{20,21}$ similar to other countries, ${ }^{22-25}$ and that the blood pressure control may be better in those with multiple antihypertensive drugs. This is consistent with meta-analyses where all main antihypertensive drug classes were shown to be equally beneficial. ${ }^{3-5}$ A conclusion of these meta-analyses was that control of blood pressure was of greater importance than prescription of antihypertensive drugs of any specific class and our findings suggest that this may hold true for AF patients with hypertension as well. It is also possible that the protective effects of prescribed RAS blockers, and more specifically ARBs, in the current study could be due to their well-documented positive effects on heart function. ${ }^{26} \mathrm{~A}$ gender difference could also be in place, as a mortality risk reduction of $\mathrm{ARB}$ compared with $\mathrm{ACE}$ inhibitors have been shown in women but not in men with heart failure. ${ }^{27}$ Having said that, ARBs are often prescribed in combined formulations with lowdose thiazides, which have previously been shown to delay the onset of heart failure in AF patients better than other antihypertensive drugs. ${ }^{28,29}$ This could also be the explanation to the lower mortality seen in men with thiazides.

The higher mortality in women aged $>80$ years prescribed either loop diuretics (or possibly also thiazides) in the current study may be explained by these women having symptomatic heart failure, which would imply a potential confounding by indication. ${ }^{30,31}$ Mortality among AF patients has been shown to increase greatly in individuals with concomitant heart failure. ${ }^{16}$ When thiazides are prescribed alone, higher doses are often used, which could result in low potassium levels.

In an earlier study, we showed that a greater proportion of $\mathrm{AF}$ patients were prescribed statins and fewer non-selective $\beta$-blockers in 
Table 3a Cox regression models for men $(n=2809)$ aged $45-104$ years with atrial fibrillation and hypertension attending the 75 primary health-care centers for a period of 1-7 years, stratified by age: 45-79 years $(n=2132)$ and $80-104$ years $(n=677)$

\begin{tabular}{|c|c|c|c|c|c|c|}
\hline & \multicolumn{2}{|c|}{ Men aged $<80$ years } & \multicolumn{2}{|c|}{ Men aged $\geqslant 80$ years } & \multicolumn{2}{|c|}{ Men all ages } \\
\hline & Model A & Model B & Model A & Model B & Model A & Model B \\
\hline & $H R(95 \% \mathrm{Cl})$ & $H R(95 \% \mathrm{Cl})$ & $H R(95 \% \mathrm{Cl})$ & $H R(95 \% \mathrm{Cl})$ & $H R(95 \% \mathrm{Cl})$ & $H R(95 \% \mathrm{Cl})$ \\
\hline \multicolumn{7}{|l|}{ Antithrombotic drugs } \\
\hline Antiplatelet agents vs. no treatment & $1.10(0.54-2.19)$ & $1.29(0.62-2.68)$ & $0.47(0.21-1.02)$ & $0.44(0.19-1.04)$ & $0.76(0.45-1.26)$ & $0.83(0.49-1.42)$ \\
\hline Anticoagulant agents vs. no treatment & $0.53(0.27-1.03)$ & $0.70(0.33-1.45)$ & $0.40(0.19-0.88)$ & $0.42(0.17-1.04)$ & $0.44(0.26-0.72)$ & $0.54(0.31-0.93)$ \\
\hline Anticoagulants vs. antiplatelets & $0.61(0.41-0.92)$ & $0.59(0.39-0.90)$ & $0.82(0.50-1.35)$ & $0.78(0.47-1.29)$ & $0.70(0.51-0.96)$ & $0.66(0.48-0.92)$ \\
\hline Digitalis & $1.35(0.91-2.02)$ & $1.27(0.85-1.91)$ & $1.13(0.71-1.79)$ & $1.06(0.66-1.70)$ & $1.29(0.95-1.74)$ & $1.22(0.90-1.64)$ \\
\hline Thiazides & $0.61(0.40-0.92)$ & $0.70(0.45-1.07)$ & $0.60(0.36-0.98)$ & $0.69(0.41-1.15)$ & $0.62(0.45-0.85)$ & $0.69(0.50-0.95)$ \\
\hline Loop diuretics & $1.31(0.86-2.01)$ & $1.25(0.79-1.96)$ & $1.52(0.92-2.51)$ & $1.52(0.89-2.62)$ & $1.39(1.01-1.93)$ & $1.33(0.93-1.88)$ \\
\hline Aldosterone antagonists & $1.52(0.93-2.46)$ & $1.51(0.90-2.51)$ & $1.17(0.66-2.08)$ & $1.01(0.56-1.83)$ & $1.40(0.96-2.02)$ & $1.32(0.90-1.95)$ \\
\hline \multicolumn{7}{|l|}{$\beta$-Blockers } \\
\hline$\beta 1$-Selective vs. no treatment & $0.93(0.58-1.50)$ & $1.09(0.66-1.78)$ & $1.01(0.60-1.70)$ & $1.09(0.64-1.85)$ & $0.99(0.69-1.40)$ & $1.12(0.77-1.59)$ \\
\hline Non-selective vs. no treatment & $0.62(0.27-1.38)$ & $0.83(0.35-1.89)$ & $0.47(0.14-1.64)$ & $0.53(0.15-1.88)$ & $0.55(0.28-1.08)$ & $0.68(0.34-1.36)$ \\
\hline Non-selective vs. $\beta 1$-selective & $0.69(0.33-1.44)$ & $0.67(0.32-1.40)$ & $0.42(0.13-1.37)$ & $0.39(0.12-1.25)$ & $0.57(0.32-1.05)$ & $0.54(0.29-1.01)$ \\
\hline \multicolumn{7}{|l|}{ RAS-blocking agents } \\
\hline ACE inhibitors vs. no treatment & $0.70(0.45-1.10)$ & $0.72(0.45-1.15)$ & $1.19(0.69-2.06)$ & $1.13(0.69-1.98)$ & $0.85(0.60-1.20)$ & $0.89(0.62-1.27)$ \\
\hline ARBs vs. no treatment & $0.66(0.36-1.20)$ & $0.73(0.39-1.36)$ & $0.44(0.19-1.05)$ & $0.38(0.16-0.91)$ & $0.60(0.37-0.97)$ & $0.63(0.38-1.04)$ \\
\hline ARBs vs. ACE inhibitors & $1.14(0.66-1.98)$ & $1.13(0.65-1.96)$ & $0.47(0.21-1.05)$ & $0.46(0.20-1.04)$ & $0.83(0.53-1.30)$ & $0.84(0.53-1.32)$ \\
\hline ACE inhibitor + thiazide vs. no treatment & $0.70(0.41-1.22)$ & $0.78(0.44-1.35)$ & $0.48(0.15-1.52)$ & $0.53(0.16-1.69)$ & $0.64(0.39-1.05)$ & $0.70(0.42-1.14)$ \\
\hline ARB + thiazide $v s$. no treatment & $0.69(0.30-1.58)$ & $0.64(0.28-1.48)$ & $0.74(0.27-2.04)$ & $0.61(0.21-1.72)$ & $0.70(0.37-1.32)$ & $0.68(0.36-1.30)$ \\
\hline ARB + thiazide vs. ACE inhibitor + thiazide & $1.39(0.54-3.58)$ & $1.28(0.49-3.35)$ & $1.21(0.35-4.19)$ & $0.84(0.21-3.39)$ & $1.40(0.66-2.97)$ & $1.27(0.59-2.72)$ \\
\hline \multicolumn{7}{|l|}{ Calcium receptor-blocking agents } \\
\hline Vessel selective vs. no treatment & $0.79(0.53-1.18)$ & $0.89(0.59-1.35)$ & $0.86(0.54-1.37)$ & $0.86(0.53-1.38)$ & $0.80(0.59-1.09)$ & $0.87(0.64-1.19)$ \\
\hline Heart active vs. no treatment & $0.81(0.35-1.89)$ & $0.90(0.38-2.12)$ & $0.41(0.10-1.71)$ & $0.37(0.08-1.75)$ & $0.64(0.31-1.32)$ & $0.70(0.34-1.45)$ \\
\hline Heart active vs. vessel selective & $1.13(0.48-2.67)$ & $0.92(0.37-2.27)$ & $0.49(0.12-2.05)$ & $0.52(0.11-2.39)$ & $0.85(0.41-1.78)$ & $0.74(0.34-1.58)$ \\
\hline Statins & $0.46(0.29-0.73)$ & $0.52(0.33-0.83)$ & $1.13(0.65-1.96)$ & $1.23(0.70-2.16)$ & $0.59(0.41-0.85)$ & $0.66(0.46-0.95)$ \\
\hline
\end{tabular}

Abbreviations: ACE, angiotensin-converting enzyme; ARB, angiotensin receptor blockers; $\mathrm{CHD}$, coronary heart disease; $\mathrm{CHF}$, congestive heart failure; $\mathrm{Cl}$, confidence interval; CVD, cerebrovascular disease; HR, hazard ratio; RAS, renin-angiotensin system.

Model A was adjusted for a propensity score comprising age group, cardiovascular co-morbidity (diabetes, CHD, CHF and CVDs), educational level and marital status. Model B was adjusted for a propensity score including all variables in Model A and all the anti-hypertensive drugs, antithrombotics and statins (except the studied drug class). Hazard ratios (HRs) with 95\% confidence intervals $(95 \% \mathrm{Cls})$ are shown.

Statistically significant results are indicated in bold.

2007 than in $2002 . .^{32}$ In the current study, prescription of statins and non-selective $\beta$-blockers was associated with lower mortality, implying that the increased statin prescription rate is of benefit to patients with $\mathrm{AF}$, whereas the lower rate of non-selective $\beta$-blockers may not have the same effect. The finding of a lower mortality in those prescribed statins may hold true as it has previously been shown that individuals prescribed statins have lower overall mortality than those not prescribed them. ${ }^{33}$ There may also be other mechanisms at play. For example, statins are known to reduce low-density lipoprotein levels and cholesterol has been discussed as a risk factor for $\mathrm{AF}^{34}$ In addition, statins have been shown to have antiarrhythmic properties. $^{35}$

The negligible effect of prescribed antithrombotics on mortality in women could be explained by our models being adjusted for other pharmacotherapies, diagnosed comorbidities and diabetes. It could also be explained by low doctors' adherence to $\mathrm{CHADS}_{2}$ treatment recommendations in Sweden. ${ }^{32}$ The good effect of anticoagulants $v s$. antiplatelets in men is in line with and supported by the current recommendation to treat $\mathrm{AF}$ patients at high risk of stroke with anticoagulants, for example, warfarin. ${ }^{36-38}$

\section{Limitations and strengths}

Despite having adjusted for many covariates using propensity scores to stabilize the complex statistical models, ${ }^{39}$ we cannot rule out the effect of residual confounding factors. In addition, patient data were extracted from primary health-care records, which may not necessarily have included details of medications prescribed by other caregivers. Besides medications, lists of diagnoses for each patient may have been incomplete, although diagnoses of cardiovascular diseases and diabetes were likely accurately recorded in the primary care records. ${ }^{40}$

Another limitation was the absence of CHF disease severity in the patient records. Also, the prescription of drugs in observational studies may be subject to confounding by indication. ${ }^{30,31}$ A further weakness of the present study was our inability to classify AF as paroxysmal, persistent or permanent. It was thus impossible to draw conclusions about which drugs were more appropriate for treating the different types of AF. Also, no information on catheter ablation procedures or Cox-Maze operations was available for the study population. Finally, we did not have access to blood pressure levels.

A key strength of this study was our ability to link patient data extracted from primary health-care records to data from national demographic and socioeconomic registers with $<1 \%$ of information missing. In addition, a study of the diagnoses recorded in the electronic patient records showed that fewer than $2 \%$ of all diagnoses were missing. ${ }^{40}$ The comprehensive nature of our data made it possible to analyze men and women with different educational levels and socioeconomic or marital statuses. In addition, the large population size (2809 men and 2793 women; over 19000 personyears of risk) was a major strength of this study. A power calculation for Cox regression analysis revealed that with a power of over $80 \%$, we were able to detect HRs $>1.5$ or $<0.67$ for dichotomous variables in both men and women. However, as we stratified the population by age, the power decreased for some models; it increased in models adjusted for sex. 
Table 3b Cox regression models for women $(n=2793)$ aged $45-104$ years with atrial fibrillation and hypertension attending the 75 primary health-care centers for a period of 1-7 years, stratified by age: $45-79$ years $(n=1539)$ and $80-104$ years $(n=1254)$

\begin{tabular}{|c|c|c|c|c|c|c|}
\hline & \multicolumn{2}{|c|}{ Women aged $<80$ years } & \multicolumn{2}{|c|}{ Women aged $\geqslant 80$ years } & \multicolumn{2}{|c|}{ Women all ages } \\
\hline & Model A & Model B & Model A & Model B & Model A & Model B \\
\hline & $H R(95 \% \mathrm{Cl})$ & $H R(95 \% \mathrm{Cl})$ & $H R(95 \% \mathrm{Cl})$ & $H R(95 \% \mathrm{Cl})$ & $H R(95 \% \mathrm{Cl})$ & $H R(95 \% \mathrm{Cl})$ \\
\hline \multicolumn{7}{|l|}{ Antithrombotic drugs } \\
\hline Antiplatelet agents vs. no treatment & $1.24(0.43-3.58)$ & $1.25(0.40-3.79)$ & $1.11(0.63-2.05)$ & $1.21(0.62-2.31)$ & $1.06(0.63-1.80)$ & $1.11(0.64-1.93)$ \\
\hline Anticoagulant agents vs. no treatment & $0.88(0.30-2.55)$ & $0.64(0.21-2.01)$ & $0.93(0.49-1.76)$ & $0.77(0.38-1.57)$ & $0.91(0.52-1.57)$ & $0.81(0.44-1.48)$ \\
\hline Anticoagulants vs. antiplatelets & $0.67(0.41-1.10)$ & $0.76(0.45-1.26)$ & $0.93(0.64-1.34)$ & $0.94(0.65-1.37)$ & $0.83(0.62-1.12)$ & $0.91(0.67-1.23)$ \\
\hline Digitalis & $1.02(0.62-1.69)$ & $0.88(0.53-1.47)$ & $1.16(0.82-1.64)$ & $1.14(0.79-1.64)$ & $1.11(0.83-1.48)$ & $1.03(0.77-1.38)$ \\
\hline Thiazides & $1.24(0.76-2.02)$ & $1.78(1.07-2.95)$ & $0.79(0.55-1.12)$ & $0.84(0.58-1.22)$ & $0.91(0.69-1.21)$ & $1.07(0.80-1.45)$ \\
\hline Loop diuretics & $2.06(1.13-3.75)$ & $2.33(1.25-4.37)$ & $1.19(0.79-1.80)$ & $1.21(0.77-1.89)$ & $1.46(1.03-2.07)$ & $1.53(1.05-2.20)$ \\
\hline Aldosterone antagonists & $1.27(0.71-2.25)$ & $1.21(0.68-2.18)$ & $1.05(0.69-1.60)$ & $1.02(0.66-1.58)$ & $1.19(0.85-1.66)$ & $1.15(0.81-1.62)$ \\
\hline \multicolumn{7}{|l|}{$\beta$-Blockers } \\
\hline$\beta 1$-Selective vs. no treatment & $0.87(0.46-1.65)$ & $0.91(0.48-1.77)$ & $0.87(0.58-1.31)$ & $0.90(0.59-1.38)$ & $0.85(0.60-1.20)$ & $0.88(0.62-1.25)$ \\
\hline Non-selective vs. no treatment & $0.52(0.17-1.64)$ & $0.59(0 . \S 8-1.94)$ & $0.77(0.36-1.64)$ & $0.76(0.35-1.64)$ & $0.62(0.33-1.17)$ & $0.66(0.34-1.25)$ \\
\hline Non-selective vs. $\beta 1$-selective & $0.54(0.19-1.50)$ & $0.52(0.19-1.46)$ & $0.88(0.44-1.76)$ & $0.86(0.41-1.75)$ & $0.76(0.43-1.35)$ & $0.73(0.41-1.31)$ \\
\hline \multicolumn{7}{|l|}{ RAS-blocking agents } \\
\hline ACE inhibitors vs. no treatment & $0.70(0.40-1.23)$ & $0.63(0.35-1.11)$ & $0.99(0.67-1.46)$ & $1.00(0.67-1.49)$ & $0.88(0.64-1.21)$ & $0.85(0.61-1.19)$ \\
\hline ARBs vs. no treatment & $0.43(0.18-1.00)$ & $0.38(0.15-0.91)$ & $0.66(0.37-1.20)$ & $0.76(0.41-1.41)$ & $0.53(0.33-0.88)$ & $0.55(0.33-0.91)$ \\
\hline ARBs vs. ACE inhibitors & $0.60(0.26-1.37)$ & $0.57(0.25-1.30)$ & $0.65(0.37-1.17)$ & $0.67(0.37-1.20)$ & $0.60(0.37-0.97)$ & $0.60(0.37-0.96)$ \\
\hline ACE inhibitor + thiazide vs. no treatment & $1.12(0.60-2.09)$ & $1.34(0.71-2.53)$ & $0.78(0.47-1.29)$ & $0.83(0.50-1.37)$ & $0.88(0.60-1.30)$ & $0.98(0.66-1.44)$ \\
\hline ARB + thiazide vs. no treatment & $0.61(0.22-1.71)$ & $0.69(0.25-1.94)$ & $0.50(0.22-1.14)$ & $0.52(0.23-1.18)$ & $0.52(0.27-0.98)$ & $0.55(0.29-1.05)$ \\
\hline ARB + thiazide vs. ACE inhibitor + thiazide & $0.62(0.21-1.89)$ & $0.60(0.20-1.82)$ & $0.67(0.27-1.68)$ & $0.63(0.25-1.57)$ & $0.62(0.31-1.25)$ & $0.59(0.29-1.20)$ \\
\hline \multicolumn{7}{|l|}{ Calcium receptor-blocking agents } \\
\hline Vessel selective vs. no treatment & $0.86(0.50-1.46)$ & $0.93(0.54-1.59)$ & $0.70(0.47-1.03)$ & $0.73(0.49-1.09)$ & $0.75(0.55-1.02)$ & $0.80(0.58-1.10)$ \\
\hline Heart active vs. no treatment & $1.17(0.52-2.67)$ & $1.15(0.49-2.59)$ & $0.71(0.37-1.35)$ & $0.61(0.32-1.19)$ & $0.90(0.54-1.48)$ & $0.78(0.47-1.32)$ \\
\hline Heart active vs. vessel selective & $1.28(0.55-2.97)$ & $1.59(0.65-3.90)$ & $1.15(0.58-2.24)$ & $1.05(0.51-2.14)$ & $1.23(0.73-2.08)$ & $1.16(0.67-2.01)$ \\
\hline Statins & $0.31(0.16-0.58)$ & $0.33(0.17-0.64)$ & $0.89(0.56-1.39)$ & $0.96(0.61-1.53)$ & $0.57(0.39-0.83)$ & $0.61(0.42-0.90)$ \\
\hline
\end{tabular}

Abbreviations: ACE, angiotensin-converting enzyme; ARB, angiotensin receptor blockers; $\mathrm{CHD}$, coronary heart disease; $\mathrm{CHF}$, congestive heart failure; $\mathrm{Cl}$, confidence interval; $\mathrm{CVD}$, cerebrovascular disease: HR, hazard ratio; RAS, renin-angiotensin system.

Model A was adjusted for a propensity score comprising age group, cardiovascular comorbidity (diabetes, CHD, CHF and CVDs), educational level and marital status. Model B was adjusted for a propensity score including all variables in Model A and all the antihypertensive drugs, antithrombotics and statins (except the studied drug class). HRs with $95 \%$ Cls are shown. Statistically significant results are indicated in bold.

Table 4 Cox regression models for men $(n=2809)$ and women $(n=2793)$ aged $45-104$ years with atrial fibrillation and hypertension attending the 75 primary health-care centers for a period of $1-7$ years stratified into two age groups: $45-79$ years (men, $n=2132$; women, $n=1539$ ) and 80-104 years (men, $n=677$; women, $n=1254$ )

\begin{tabular}{|c|c|c|c|c|c|c|c|c|}
\hline & & & \multicolumn{3}{|c|}{ Men } & \multicolumn{3}{|c|}{ Women } \\
\hline & & All ages & $<80$ years & $\geqslant 80$ years & All ages & $<80$ years & $\geqslant 80$ years & All ages \\
\hline & $\mathrm{n}$ & $H R(95 \% \mathrm{Cl})$ & $H R(95 \% \mathrm{Cl})$ & $H R(95 \% \mathrm{Cl})$ & $H R(95 \% C l)$ & $H R(95 \% \mathrm{Cl})$ & $H R(95 \% \mathrm{Cl})$ & $H R(95 \% \mathrm{Cl})$ \\
\hline \multicolumn{9}{|c|}{ Number of antihypertensive drugs } \\
\hline $0-1$ & 861 & 1 (ref) & 1 (ref) & 1 (ref) & 1 (ref) & 1 (ref) & 1 (ref) & 1 (ref) \\
\hline 2 & 1516 & $0.85(0.63-1.14)$ & $0.94(0.54-1.66)$ & $0.88(0.46-1.69)$ & $0.95(0.63-1.45)$ & $0.41(0.19-0.91)$ & $0.88(0.52-1.50)$ & $0.74(0.48-1.13)$ \\
\hline 3 & 1719 & $0.80(0.60-1.08)$ & $0.92(0.52-1.65)$ & $0.48(0.23-0.98)$ & $0.76(0.49-1.18)$ & $0.65(0.32-1.35)$ & $0.94(0.57-1.56)$ & $0.84(0.56-1.27)$ \\
\hline $4-5$ & 1506 & $0.62(0.45-0.86)$ & $0.51(0.26-1.00)$ & $0.62(0.29-1.30)$ & $0.57(0.35-0.94)$ & $0.68(0.33-1.41)$ & $0.58(0.33-1.02)$ & $0.63(0.40-0.98)$ \\
\hline$P$-value for trend & & 0.005 & 0.079 & 0.063 & 0.021 & 0.55 & 0.096 & 0.075 \\
\hline
\end{tabular}

Abbreviations: $\mathrm{Cl}$, confidence interval; $\mathrm{HR}$, hazard ratio; RAS, renin-angiotensin system.

The relative risk associated with the total number of prescribed antihypertensive drugs (thiazides, potassium-saving diuretics, $\beta$-blockers, RAS blockers and calcium antagonists) was calculated. The models were adjusted for age group, comorbidities, educational level, marital status and prescribed drugs other than antihypertensives (antithrombotic drugs, digitalis, loop diuretics and statins). The model for the whole sample was also adjusted for sex.

Statistically significant results are indicated in bold.

Although many previous follow-up studies of AF have used hospital data for severely ill patients, the current study used data from primary care, which may better reflect the risks associated with $\mathrm{AF}$ in the society as a whole. In addition, randomized controlled trials often exclude individuals with comorbidities, such as AF patients with concomitant diabetes and CHF. In the current study, we were able to include these patients in the analyses. Our findings may thus be more representative of the variety of AF patients attending PHCCs today.
In conclusion, $\mathrm{AF}$ patients with hypertension prescribed statins had lower relative mortality risks, suggesting that statins were of great benefit to these patients. Furthermore, prescription of non-selective $\beta$-blockers and ARBs was associated with lower mortality in sexadjusted models. This needs to be further explored in future studies of AF patients with hypertension in other types of clinical settings.

\section{CONFLICT OF INTEREST}

The authors declare no conflict of interest. 


\section{ACKNOWLEDGEMENTS}

This work was supported by grants to KS from the Swedish Research Council (K2009-70X-15428-05-3; K2012-70X-15428-08-3), to JS from the Swedish Freemasons Foundation and ALF funding from Region Skåne awarded to JS and KS.

1 Chobanian AV, Bakris GL, Black HR, Cushman WC, Green LA, Izzo JL Jr., Jones DW, Materson BJ, Oparil S, Wright JT Jr., Roccella EJ. The Seventh Report of the Joint National Committee on Prevention, Detection, Evaluation, and Treatment of High Blood Pressure: the JNC 7 report. JAMA 2003; 289: 2560-2572.

2 Mancia G, De Backer G, Dominiczak A, Cifkova R, Fagard R, Germano G, Grassi G, Heagerty AM, Kjeldsen SE, Laurent S, Narkiewicz K, Ruilope L, Rynkiewicz A, Schmieder RE, Struijker Boudier HA, Zanchetti A, Vahanian A, Camm J, De Caterina R, Dean V, Dickstein K, Filippatos G, Funck-Brentano C, Hellemans I, Kristensen SD, McGregor K, Sechtem U, Silber S, Tendera M, Widimsky P, Zamorano JL, Kjeldsen SE, Erdine S, Narkiewicz K, Kiowski W. Agabiti-Rosei E, Ambrosioni E, Cifkova R, Dominiczak A, Fagard R, Heagerty AM, Laurent S, Lindholm LH, Mancia G, Manolis A, Nilsson PM, Redon J, Schmieder RE, Struijker-Boudier HA, Viigimaa M, Filippatos G, Adamopoulos S, Agabiti-Rosei E, Ambrosioni E, Bertomeu V, Clement D, Erdine S, Farsang C, Gaita D, Kiowski W, Lip G, Mallion JM, Manolis AJ, Nilsson PM, O'Brien E, Ponikowski P, Redon J, Ruschitzka F, Tamargo J, van Zwieten P, Viigimaa M, Waeber B, Williams B, Zamorano JL. 2007 Guidelines for the management of arterial hypertension: the task force for the management of arterial hypertension of the European Society of Hypertension (ESH) and of the European Society of Cardiology (ESC). Eur Heart J 2007; 28: 1462-1536.

3 Turnbull F. Effects of different blood-pressure-lowering regimens on major cardiovascular events: results of prospectively-designed overviews of randomised trials. Lancet 2003; 362: 1527-1535.

4 Turnbull F, Neal B, Algert C, Chalmers J, Chapman N, Cutler J, Woodward M, MacMahon S. Effects of different blood pressure-lowering regimens on major cardiovascular events in individuals with and without diabetes mellitus: results of prospectively designed overviews of randomized trials. Arch Intern Med 2005; 165: 1410-1419.

5 Turnbull F, Neal B, Ninomiya T, Algert C, Arima H, Barzi F, Bulpitt C, Chalmers J, Fagard R, Gleason A, Heritier S, Li N, Perkovic V, Woodward M, MacMahon S. Effects of different regimens to lower blood pressure on major cardiovascular events in older and younger adults: meta-analysis of randomised trials. BMJ 2008; 336: 1121-1123.

6 Knottnerus JA, Tugwell P. Requirements for utilizing health care-based data sources for research. J Clin Epidemiol 2011; 64: 1051-1053.

7 Wandell PE. A survey of subjects with present or previous atrial fibrillation in a swedish community. Scand J Prim Health Care 2001; 19: 20-24.

8 Bajpai A, Savelieva I, Camm AJ. Treatment of atrial fibrillation. Br Med Bull 2008; 88 75-94.

9 Feinberg WM, Blackshear JL, Laupacis A, Kronmal R, Hart RG. Prevalence, age distribution, and gender of patients with atrial fibrillation. Analysis and implications. Arch Intern Med 1995; 155: 469-473.

10 Wandell P, Carlsson AC, Sundquist K, Johansson SE, Sundquist J. Effect of cardiovascular drug classes on all-cause mortality among atrial fibrillation patients treated in primary care in Sweden: a cohort study. Eur J Clin Pharmacol 2013; 69: 279-287.

11 Carlsson AC, Wandell P, Sundquist K, Johansson SE, Sundquist J. Differences and time trends in drug treatment of atrial fibrillation in men and women and doctors' adherence to warfarin therapy recommendations: a Swedish study of prescribed drugs in primary care in 2002 and 2007. Eur J Clin Pharmacol 2013; 69: 245-253.

12 Douma S, Petidis K, Doumas M, Papaefthimiou P, Triantafyllou A, Kartali N, Papadopoulos N, Vogiatzis K, Zamboulis C. Prevalence of primary hyperaldosteronism in resistant hypertension: a retrospective observational study. Lancet 2008; 371: 1921-1926.

13 Furberg CD. Treatment of hypertension: failing report card. Am J Hypertens 2009; 22 : $1-2$

14 Sundquist $\mathrm{K}, \mathrm{Li} \mathrm{X}$. Coronary heart disease risks in first- and second-generation immigrants in sweden: a follow-up study. J Intern Med 2006; 259: 418-427.

15 Wandell PE, Carlsson AC, Sundquist K, Johansson SE, Sundquist J. Total mortality among levothyroxine-treated women with atrial fibrillation in Swedish primary health care. Int J Cardiol 2011; 152: 147-148.

16 Seiler J, Stevenson WG. Atrial fibrillation in congestive heart failure. Cardiol Rev 2010; 18: 38-50.

17 Friberg L, Hammar N, Ringh M, Pettersson H, Rosenqvist M. Stroke prophylaxis in atrial fibrillation: Who gets it and who does not? Report from the Stockholm cohortstudy on atrial fibrillation (SCAF-study). Eur Heart J 2006; 27: 1954-1964.

18 Fuster V, Ryden LE, Cannom DS, Crijns HJ, Curtis AB, Ellenbogen KA, Halperin JL, Le Heuzey JY, Kay GN, Lowe JE, Olsson SB, Prystowsky EN, Tamargo JL, Wann S, Smith SC Jr., Jacobs AK, Adams CD, Anderson JL, Antman EM, Halperin JL, Hunt SA, Nishimura R, Ornato JP, Page RL, Riegel B, Priori SG, Blanc JJ, Budaj A, Camm AJ, Dean V, Deckers JW, Despres C, Dickstein K, Lekakis J, McGregor K, Metra M, Morais J, Osterspey A, Tamargo JL, Zamorano JL. ACC/AHA/ESC 2006 guidelines for the management of patients with atrial fibrillation: full text: a report of the American College of Cardiology/American Heart Association Task Force on practice guidelines and the European Society Of Cardiology Committee for practice guidelines (writing committee to revise the 2001 guidelines for the management of patients with atrial fibrillation) developed in collaboration with the european heart rhythm association and the heart rhythm society. Europace 2006; 8: 651-745.

19 Dahabreh IJ, Sheldrick RC, Paulus JK, Chung M, Varvarigou V, Jafri H, Rassen JA, Trikalinos TA, Kitsios GD. Do observational studies using propensity score methods agree with randomized trials? A systematic comparison of studies on acute coronary syndromes. Eur Heart J 2012; 33: 1893-1901.

20 Carlsson AC, Wandell PE, Journath G, de Faire U, Hellenius ML. Factors associated with uncontrolled hypertension and cardiovascular risk in hypertensive 60-year-old men and women—a population-based study. Hypertens Res 2009; 32: 780-785.

21 Journath G, Hellenius ML, Carlsson AC, Wandell PE, Nilsson PM. Physicians' gender is associated with risk factor control in patients on antihypertensive and lipid lowering treatment. Blood Press 2010; 19: 240-248.

22 Berlowitz DR, Ash AS, Hickey EC, Friedman RH, Glickman M, Kader B, Moskowitz MA. Inadequate management of blood pressure in a hypertensive population. New Eng/ J Med 1998; 339: 1957-1963.

23 Grandi AM, Maresca AM, Sessa A, Stella R, Ponti D, Barlocco E, Banfi F, Venco A. Longitudinal study on hypertension control in primary care: The Insubria study. Am J Hypertens 2006; 19: 140-145.

24 Ong KL, Cheung BM, Man YB, Lau CP, Lam KS. Prevalence, awareness, treatment, and control of hypertension among united states adults 1999-2004. Hypertension 2007; 49: 69-75.

25 Volpe M, Tocci G, Trimarco B, Rosei EA, Borghi C, Ambrosioni E, Menotti A, Zanchetti A, Mancia G. Blood pressure control in italy: results of recent surveys on hypertension. J Hypertens 2007; 25: 1491-1498.

26 Farsang $C$. Indications for and utilization of angiotensin receptor ii blockers in patients at high cardiovascular risk. Vasc Health Risk Manag 2011; 7: 605-622.

27 Hudson M, Rahme E, Behlouli H, Sheppard R, Pilote L. Sex differences in the effectiveness of angiotensin receptor blockers and angiotensin converting enzyme inhibitors in patients with congestive heart failure - a population study. Eur J Heart Fail 2007; 9: 602-609.

28 ALLHAT Officers and Coordinators for the ALLHAT Collaborative Research Group. Major outcomes in high-risk hypertensive patients randomized to angiotensin-converting enzyme inhibitor or calcium channel blocker vs. diuretic: the Antihypertensive and Lipid-Lowering Treatment to Prevent Heart Attack Trial (ALLHAT). JAMA 2002; 288: 2981-2997.

29 Davis BR, Piller LB, Cutler JA, Furberg C, Dunn K, Franklin S, Goff D, Leenen F, Mohiuddin S, Papademetriou V, Proschan M, Ellsworth A, Golden J, Colon P, Crow R. Role of diuretics in the prevention of heart failure: the antihypertensive and lipid-lowering treatment to prevent heart attack trial. Circulation 2006; 113. 2201-2210

30 de Koning JS, Klazinga NS, Koudstaal PJ, Prins A, Borsboom GJ, Mackenbach JP. The role of 'confounding by indication' in assessing the effect of quality of care on disease outcomes in general practice: results of a case-control study. BMC Health Serv Res 2005; 5 : 10

31 Grobbee DE, Hoes AW. Confounding and indication for treatment in evaluation of drug treatment for hypertension. BMJ 1997; 315: 1151-1154.

32 Carlsson AC, Wandell P, Sundquist K, Johansson SE, Sundquist J. Differences and time trends in drug treatment of atrial fibrillation in men and women and doctors' adherence to warfarin therapy recommendations: a Swedish study of prescribed drugs in primary care in 2002 and 2007. Eur J Clin Pharmacol 2012; 69: 245-253.

33 Baigent C, Keech A, Kearney PM, Blackwell L, Buck G, Pollicino C, Kirby A, Sourjina T, Peto R, Collins R, Simes R. Efficacy and safety of cholesterol-lowering treatment: prospective meta-analysis of data from 90,056 participants in 14 randomised trials of statins. Lancet 2005; 366: 1267-1278.

34 Goonasekara CL, Balse E, Hatem S, Steele DF, Fedida D. Cholesterol and cardiac arrhythmias. Expert Rev Cardiovasc Ther 2010; 8: 965-979.

35 Bachmann JM, Majmudar M, Tompkins C, Blumenthal RS, Marine JE. Lipid-altering therapy and atrial fibrillation. Cardiol Rev 2008; 16: 197-204.

36 Henriksson KM, Farahmand B, Johansson S, Asberg S, Terent A, Edvardsson N. Survival after stroke - the impact of chads2 score and atrial fibrillation. Int J Cardiol 2010; 141: 18-23.

37 Lip GY, Frison L, Halperin JL, Lane DA. Identifying patients at high risk for stroke despite anticoagulation: a comparison of contemporary stroke risk stratification schemes in an anticoagulated atrial fibrillation cohort. Stroke 2010; 41: 2731-2738.

38 Lip GY, Nieuwlaat R, Pisters R, Lane DA, Crijns HJ. Refining clinical risk stratification for predicting stroke and thromboembolism in atrial fibrillation using a novel risk factor-based approach: The Euro Heart Survey on Atrial Fibrillation. Chest 2010; 137: 263-272.

39 Cepeda MS, Boston R, Farrar JT, Strom BL. Comparison of logistic regression versus propensity score when the number of events is low and there are multiple confounders. Am J Epidemiol 2003; 158: 280-287.

40 Sundquist K, Chaikiat A, Leon VR, Johansson SE, Sundquist J. Country of birth, socioeconomic factors, and risk factor control in patients with type 2 diabetes: a Swedish study from 25 primary health-care centres. Diabetes Metab Res Rev 2011; 27: 244-254. 